\title{
CONVERGENCE OF A RANDOM ITERATION SCHEME TO A RANDOM FIXED POINT
}

\author{
BINAYAK S. CHOUDHURY \\ Scottish Church College, Department of Mathematics \\ 1 and 3, Urquhurt Square, Calcutta \\ West Bengal INDIA, PIN-700-006
}

(Received February, 1994; revised November, 1994)

\begin{abstract}
This paper discusses the convergence of random Ishikawa iteration scheme to a random fixed point for a certain class of random operators.

Key words: Random fixed point, random Ishikawa iteration, Tricomi's condition, Hilbert space, random operator.
\end{abstract}

AMS subject classification: $47 \mathrm{H} 10,47 \mathrm{H} 40$.

\section{Introduction}

In recent years the study of random fixed points have attracted a great amount of attention. Discussions on random fixed points may be found in works such as [1], [2], [6], and [7]. We review the following concepts which are essentials for the purpose of our discussion. Throughout this paper, $(T, \Sigma)$ denotes a measurable space, and $H$ denotes a separable Hilbert space.

A function $f: T \rightarrow H$ is said to be measurable if $f^{-1}(B) \in \Sigma$ for every Borel subset $B$ of $H$.

Let $C$ be any subset of $H$. A function $f: T \rightarrow C$ is said to be measurable if $f^{-1}(B \cap C) \in \Sigma$ for every Borel subset $B$ of $H$.

A function $F: T \times H \rightarrow H$ is said to be $H$-continuous if $F(t, \cdot): H \rightarrow H$ is continuous for every $t \in T$.

A function $F: T \times H \rightarrow H$ is said to be a random operator if $F(\cdot, x): T \rightarrow H$ is measurable for every $x \in H$.

A measurable function $g: T \rightarrow H$ is said to be a random fixed point of $F: T \times H \rightarrow H$ if $F(t, g(t))=g(t)$ for all $t \in T$.

The Ishikawa iteration scheme was obtained in [5]. We define the random Ishikawa iteration scheme in an analogous manner as follows: follows:

Let $g_{0}: T \rightarrow H$ be any measurable function. The functions below are iteratively defined as

where

$$
g_{n+1}(t)=\alpha_{n} F\left(t, h_{n}(t)\right)+\left(1-\alpha_{n}\right) g_{n}(t), \quad n \geq 0, \quad t \in T .
$$

$$
h_{n}(t)=\beta_{n} F\left(t, g_{n}(t)\right)+\left(1-\beta_{n}\right) g_{n}(t), \quad n \geq 0, \quad t \in T .
$$

and $\left\{\alpha_{n}\right\}$ and $\left\{\beta_{n}\right\}$ are sequences of real numbers such that 


$$
\begin{gathered}
0<\alpha_{n}, \beta_{n}<1 \text { for all } n \geq 0 \\
\lim _{n \rightarrow \infty} \sup \beta_{n}=M<1
\end{gathered}
$$

and

$$
\sum_{n=1}^{\infty} \alpha_{n} \beta_{n}=\infty
$$

Let $C \subset H, k: C \rightarrow C$ is said to satisfy Tricomi's condition in $C$ if $p \in C$ and $k(p)=p$ imply

$$
\|k(x)-p\| \leq\|x-p\| \text { for all } x \in C .
$$

The following lemma was proved in [5]:

Lemma: $H$ is a Hilbert space; therefore for any $x, y, z \in H$ and any real $\lambda$

$$
\|\lambda x+(1-\lambda) y-z\|^{2}=\lambda\|x-z\|^{2}+(1-\lambda)\|y-z\|^{2}-\lambda(1-\lambda)\|x-y\|^{2}
$$

\section{Main Result}

Theorem 1: Let $H$ be a separable Hilbert space. $F: T \times H \rightarrow H$ is an $H$-continuous random operator in which case there exists $f: T \rightarrow H$ (not necessarily measurable) such that

$$
\|F(t, x)-f(t)\| \leq\|x-f(t)\|
$$

for all $t \in T$ and $x \in H$.

Then, for any measurable function $g_{0}: T \rightarrow H$, the sequence of functions $\left\{g_{n}\right\}$ defined by the random Ishikawa iteration scheme, if convergent, converges to a random fixed point of $F$.

Proof: For any $t \in T$,

$$
\begin{gathered}
\left\|g_{n+1}(t)-f(t)\right\|^{2} \\
=\left\|\alpha_{n} F\left(t, h_{n}(t)\right)+\left(1-\alpha_{n}\right) g_{n}(t)-f(t)\right\|^{2} \\
=\alpha_{n}\left\|F\left(t, h_{n}(t)\right)-f(t)\right\|^{2}+\left(1-\alpha_{n}\right)\left\|g_{n}(t)-f(t)\right\|^{2} \\
-\alpha_{n}\left(1-\alpha_{n}\right)\left\|F\left(t, h_{n}(t)\right)-g_{n}(t)\right\|^{2}(\text { by }(7)) \\
\leq \alpha_{n}\left\|F\left(t, h_{n}(t)\right)-f(t)\right\|^{2}+\left(1-\alpha_{n}\right)\left\|g_{n}(t)-f(t)\right\|^{2}(\text { by }(3)) \\
\leq \alpha_{n}\left\|h_{n}(t)-f(t)\right\|^{2}+\left(1-\alpha_{n}\right)\left\|g_{n}(t)-f(t)\right\|^{2}(\text { by }(8)) \\
\leq\left\|g_{n}(t)-f(t)\right\|^{2}-\alpha_{n} \beta_{n}\left(1-\beta_{n}\right)\left\|F\left(t, g_{n}(t)\right)-g_{n}(t)\right\|^{2}
\end{gathered}
$$

(by using (2), (7) and (8)).

It further implies that

$$
\begin{gathered}
\sum_{n=0}^{N} \alpha_{n} \beta_{n}\left(1-\beta_{n}\right)\left\|F\left(t, g_{n}(t)\right)-g_{n}(t)\right\|^{2} \\
\leq\left\|g_{0}(t)-f(t)\right\|^{2}-\left\|g_{N+1}(t)-f(t)\right\|^{2} \\
\leq\left\|g_{0}(t)-f(t)\right\|^{2}<\infty .
\end{gathered}
$$


For $M^{\prime}$ satisfying $M<M^{\prime}<1$, there exists a positive integer $m_{0}$ such that $\beta_{m}<M^{\prime}$ for all $m \geq m_{0}$ (by (4)). Therefore, $1-\beta_{m}>1-M^{\prime}>0$ for all $m \geq m_{0}$, or

(9) and (10) imply,

$$
\sum_{m=m_{0}}^{\infty} \alpha_{m} \beta_{m}\left(1-\beta_{m}\right) \geq\left(1-M^{\prime}\right) \sum_{m=m_{0}}^{\infty} \alpha_{m} \beta_{m}=\infty
$$

$$
\lim _{n \rightarrow \infty} \inf \left\|F\left(t, g_{n}(t)\right)-g_{n}(t)\right\|=0 \text { for all } t \in T .
$$

Hence, if $\left\{g_{n}(t)\right\}$ converges, for example to $g(t), F\left(t, g_{n}(t)\right)$ also converges to $g(t)$.

Since $F: T \times H \rightarrow H$ is an $H$-continuous random operator and $H$ is separable, $\left\{g_{n}\right\}$ is a sequence of measurable functions [4]. Therefore, $g=\lim _{n \rightarrow \infty} g_{n}$ is measurable. Furthermore, $F$ is $H$ continuous; thus, for all $t \in T$,

$$
\begin{gathered}
g(t)=\lim _{n \rightarrow \infty} g_{n}(t)=\lim _{n \rightarrow \infty} F\left(t, g_{n}(t)\right) \\
=F\left(t \lim _{n \rightarrow \infty} g_{n}(t)\right)=F(t, g(t)) .
\end{gathered}
$$

Hence, $g$ is a random fixed point of $F$.

Therefore, $\left\{g_{n}\right\}$ (if convergent) converges to a random fixed point of $F$.

Theorem 2: Let $C \subset H$ be a convex and compact subset and $F: T \times C \rightarrow C$ satisfies

a) $\quad F$ is $H$-continuous;

b) there exists $f: T \rightarrow C$ such that $\|F(t, x)-f(t)\| \leq\|x-f(t)\|$ for all $t \in T$ and $x \in C$;

and

c) $\quad F(t, \cdot): C \rightarrow C$ satisfies Tricomi's condition in $C$ for every $t \in T$.

Then, for any measurable function $g_{0}: T \rightarrow C$, the sequence $\left\{g_{n}\right\}$ of measurable functions constructed by the random Ishikawa iteration scheme converges to a random fixed point of $F$.

Proof: Since $C$ is convex and compact, $H$ is a separable Hilbert space and $F$ is an $H$ continuous random operator and $\left\{g_{n}\right\}$ is a sequence of measurable functions from $C$ to $C$. Proceeding exactly as in Theorem 1, we obtain (as in (11))

$$
\lim _{n \rightarrow \infty} \inf \left\|F\left(t, g_{n}(t)\right)-g_{n}(t)\right\|=0 .
$$

Therefore, for fixed $t \in T$, there exists $\left\{g_{n_{i}}(t)\right\} \subset\left\{g_{n}(t)\right\}$ such that

$$
\lim _{i \rightarrow \infty}\left\|F\left(t, g_{n_{i}}(t)\right)-g_{n_{i}}(t)\right\|=0 .
$$

Since $C$ is compact, there exists $\left\{g_{n_{i_{k}}}(t) \subset\left\{g_{n_{i}}(t)\right\}\right.$, such that $\left\{g_{n_{i_{k}}}(t)\right\}$ is convergent.

Let

$$
\lim _{k \rightarrow \infty} g_{n_{i_{k}}}(t)=g(t)
$$

From (12) and (13), and since $\left\{g_{n_{i_{k}}}(t)\right\} \subset\left\{g_{n_{i}}(t)\right\}$, we have

or

$$
\lim _{k \rightarrow \infty} F\left(t, g_{n_{i_{k}}}(t)\right)=g(t)
$$

$$
F(t, g(t))=g(t) \text { (since } F \text { is } H \text {-continuous). }
$$

Hence, for fixed $t \in T, g(t)$ is a fixed point of $F(t, \cdot)$.

For any fixed $t \in T$,

$$
\begin{gathered}
\left\|g_{n+1}(t)-g(t)\right\|^{2}=\left\|\alpha_{n} F\left(t, h_{n}(t)\right)+\left(1-\alpha_{n}\right) g_{n}(t)-g(t)\right\|^{2} \\
=\alpha_{n}\left\|F\left(t, h_{n}(t)\right)-g(t)\right\|^{2}+\left(1-\alpha_{n}\right)\left\|g_{n}(t)-g(t)\right\|^{2}
\end{gathered}
$$




$$
\begin{gathered}
-\alpha_{n}\left(1-\alpha_{n}\right)\left\|F\left(t, h_{n}(t)\right)-g_{n}(t)\right\|^{2} \text { (by (7)) } \\
\leq \alpha_{n}\left\|h_{n}(t)-g(t)\right\|^{2}+\left(1-\alpha_{n}\right)\left\|g_{n}(t)-g(t)\right\|^{2}(\text { by }(3) \text { and Tricomi's condition }(6)) \\
=\alpha_{n}\left\|\beta_{n} F\left(t, g_{n}(t)\right)+\left(1-\beta_{n}\right) g_{n}(t)-g(t)\right\|^{2}+\left(1-\alpha_{n}\right)\left\|g_{n}(t)-g(t)\right\|^{2} \\
=\alpha_{n}\left(\beta_{n}\left\|F\left(t, g_{n}(t)\right)-g(t)\right\|^{2}+\left(1-\beta_{n}\right)\left\|g_{n}(t)-g(t)\right\|^{2}\right. \\
\left.-\beta_{n}\left(1-\beta_{n}\right)\left\|F\left(t, g_{n}(t)\right)-g_{n}(t)\right\|^{2}\right)+\left(1-\alpha_{n}\right)\left\|g_{n}(t)-g(t)\right\|^{2}(\text { by }(7)) \\
\leq \alpha_{n}\left(\beta_{n}\left\|g_{n}(t)-g(t)\right\|^{2}+\left(1-\beta_{n}\right)\left\|g_{n}(t)-g(t)\right\|^{2}\right) \\
+\left(1-\alpha_{n}\right)\left\|g_{n}(t)-g(t)\right\|^{2}(\text { by }(3) \text { and Tricomi's condition }(6)) \\
=\alpha_{n}\left\|g_{n}(t)-g(t)\right\|^{2}+\left(1-\alpha_{n}\right)\left\|g_{n}(t)-g(t)\right\|^{2} \\
=\left\|g_{n}(t)-g(t)\right\|^{2} .
\end{gathered}
$$

Therefore, for $t \in T$,

$$
\left\|g_{n+1}(t)-g(t)\right\| \leq\left\|g_{n}(t)-g(t)\right\| .
$$

Since $\left\{g_{n_{i_{k}}}(t)\right\} \rightarrow g(t)$, given $\epsilon>0$, there exists $n_{i_{k_{0}}}$ such that

By virtue of (15),

$$
\left\|g_{n_{i_{k_{0}}}}(t)-g(t)\right\|<\epsilon
$$

$$
\left\|g_{n}(t)-g(t)\right\|<\epsilon \text { for all } n \geq n_{i_{k_{0}}} .
$$

Therefore, for $t \in T, \lim _{n \rightarrow \infty} g_{n}(t)=g(t)$. Since $\left\{g_{n}\right\}$ is a sequence of measurable functions, $g$ is also measurable. Thus, $g: T \rightarrow C$ is a random fixed point of $F: T \times C \rightarrow C$.

\section{Acknowledgement}

I acknowledge the kind help extended to me by Professor J.N. Das, Department of Applied Mathematics, University of Calcutta, during the preparation of this paper.

\section{References}

[1] Beg, I. and Shahzad, N., Random fixed points and approximations in random convex metric spaces, J. Appl. Math. Stoch. Anal. 6:3 (1993), 237-246.

[2] Bharucha-Reid, A.T., Fixed point theorems in probabilistic analysis, Bull. Amer. Math. Soc. 82 (1976), 641-657.

[3] Cohn, D.L., Measure Theory, Birkhauser, Boston 1980.

[4] Himmelberg, C.J., Measurable relations, Fund. Math. LXXXVII (1975), 53-71.

[5] Ishikawa, S., Fixed points by a new iteration method, Proc. Amer. Math. Soc. 44 (1974), 147-150.

[6] Itoh, S., Random fixed point theorems with an application to random differential equations in Banach spaces, J. Math. Anal. Appl. 67 (1979), 261-273.

[7] Sehgal, V.M. and Waters, C., Some random fixed point theorems for condensing operators, Proc. Amer. Math. Soc. 90 (1984), 425-429. 


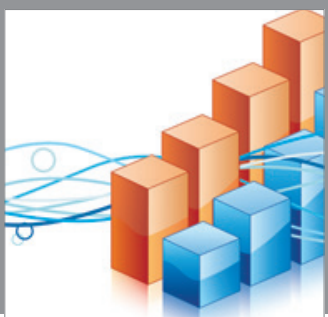

Advances in

Operations Research

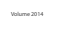

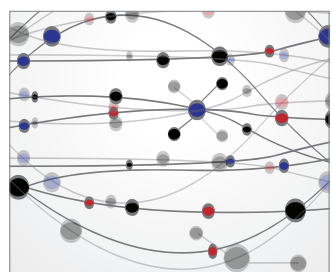

\section{The Scientific} World Journal
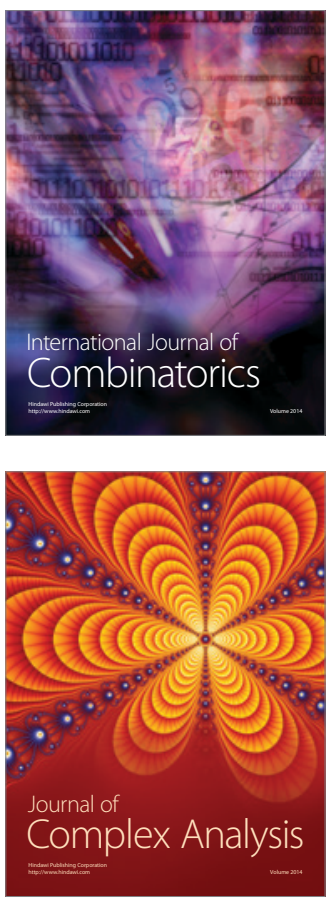

International Journal of

Mathematics and

Mathematical

Sciences
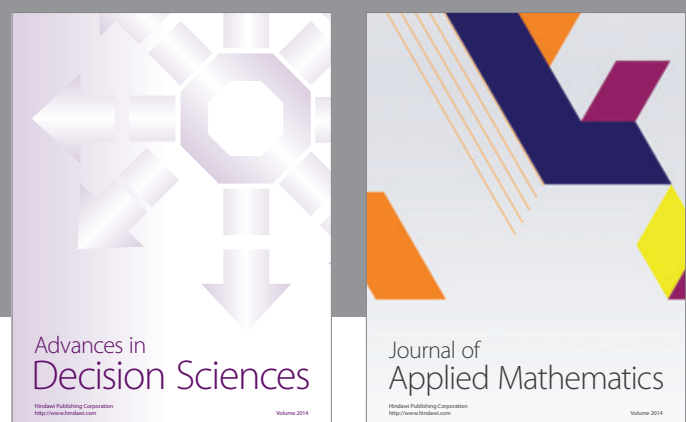

Journal of

Applied Mathematics
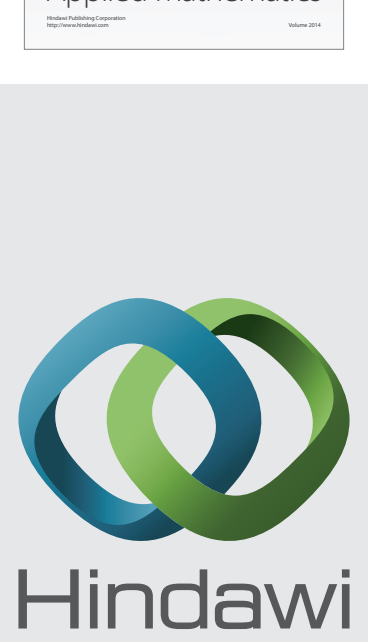

Submit your manuscripts at http://www.hindawi.com
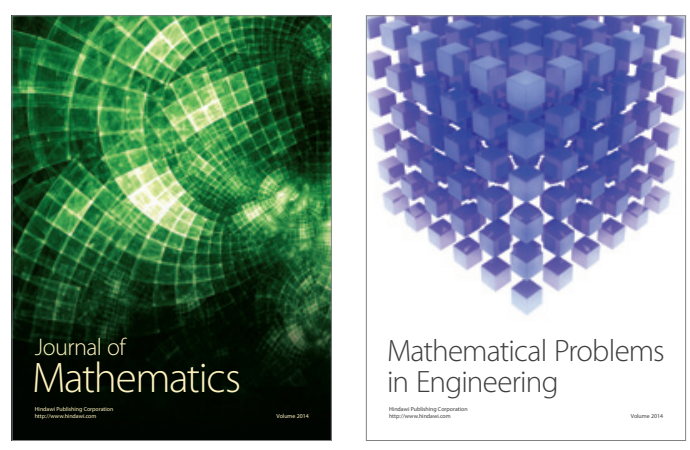

Mathematical Problems in Engineering
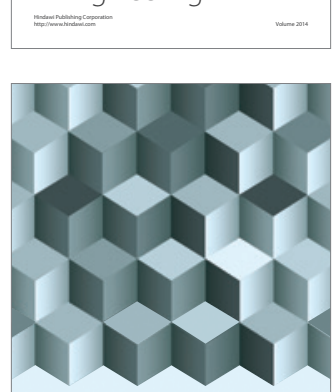

Journal of

Function Spaces
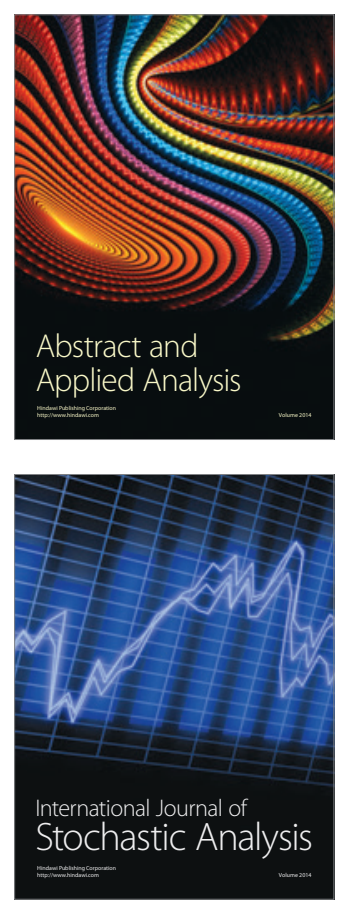

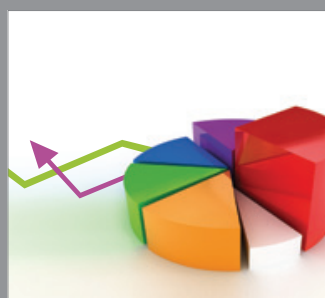

ournal of

Probability and Statistics

Promensencen
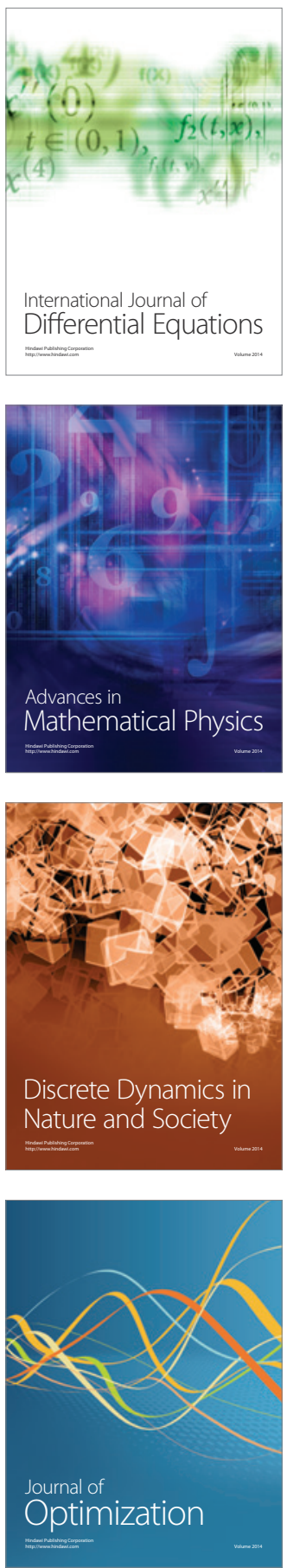